\title{
New Approach of Game Theory for Seller's Price Selecting Strategies in Bi-Level Programming
}

\author{
K. Shahanaghi ${ }^{1} \&$ M. Keyvani $\operatorname{Rad}^{2}$ \\ ${ }^{1}$ Academic member of School of Industrial Engineering, Iran University of Science and Technology, Tehran, \\ Iran \\ ${ }^{2}$ Ph.D. student of School of Industrial Engineering, Iran University of Science and Technology, Tehran, Iran. \\ Correspondence: M. Keyvani Rad, Ph.D. student of School of Industrial Engineering, Iran University of Science \\ and Technology, Tehran, Iran. Tel: 9821-4441-6809. E-mail: keyvanirad@gmail.com
}

Received: December 9, 2015

Accepted: December 21, $2015 \quad$ Online Published: February 2, 2016

doi:10.5539/mas.v10n4p76

URL: http://dx.doi.org/10.5539/mas.v10n4p76

\begin{abstract}
The relationships between the members of supply chain were modeled in many researches, such as cooperative and non-cooperative situation. In our paper, the main question is how much and for which price should each seller offer her product to maximize the profit. In the proposed methodology, Bi-level programming is used for modeling and then GAMS (general algebraic modeling system) language for solving the problem. In the presented model, the first level, called upper sub-problem and supposed as leader is trying to maximize each seller profits by obtaining the optimal offered quantity of individual seller. The objective of follower (buyer) is at second level. The lower sub-problem uses the results of the seller's model and then maximizes its profit. These optimizations are obtained with regard to the some other constraints. Similar the other game theories problems, the Nash equilibrium point(s) is (are) the optimum decision of this seller-buyer supply chain. A numerical example is employed to illustrate the application of the proposed method.
\end{abstract}

Keywords: Bi-level programming, Nash equilibrium, seller-buyer, supply chain management

\section{Introduction}

In recent decades, big changes happen in different industries, so more competition is observed in selling markets. Each members of supply chain such as seller and buyer will try to maximize its own profit or on the other hand minimize its costs. In seller-buyer models, the seller produces a product, and after that in a wholesale price sells that to the buyer. Buyer in her turn retails the mention product to the consumer (Yang \& Zhou, 2006; Chen et al, 2006; Dai et al, 2005)

A wide literature exists on the suppliers' competition and their strategic choices. In categorizing the strategic behavior of seller-buyer supply chain, it could be falls into game theory decision making. Nash equilibrium is one of the solutions which are accepted by all players. Also, using this solution concept is very common. Hence, at first the profit of each seller will be calculated in different possible strategy. Then, after considering the buyer conditions Nash equilibrium points and its optimum selected strategy of each seller would be found. On the other hand the proposed method is a seller selecting with regard to the parameters, decision variables and objects functions of not only sellers but the buyer. Generally, each seller are intended in selling its products as high as it is possible, but exist competition forced seller to offer acceptable prices.

The strategy of offering prices of seller depends on other seller (the opponents) behavior, total demand and many other factors. For a seller, it is so significant and critical to select a good price choosing strategy according to its opponents' behavior and other conditions. Hence, it's better for sellers to solve their problem by game theory.

The game based methods, which will be used in this article, are more useful in solving these problems. The game based problem solutions can be classified as follows in (Soleymani et al, 2007; Ferrero et al, 1998; Shahidehpour et al, 2002):

a. Complete and incomplete information.

b. Cooperative and non-cooperative games.

c. Perfect and imperfect information.

Generally, previous researches about finding the best strategy for producing and ordering in the chain of seller and buyer are categorized in three main groups. These categories are as follows:

a. When the demand is constant in seller-buyer supply chain.

b. When demand is varies in seller-buyer supply chain. 
c. When the model doesn't consider the logistic cost including setup/ordering and holding/carrying costs (Esmaeili et al, 2009).

Chiang et al (1994), Corbett and de Groote (2000) and Viswanathan and Wang (2003) considered different coordination and non-coordination mechanisms in modeling the behavior of the seller and the buyer. These mechanisms contain quantity discount (as a coordination mechanism).

Demand is sensitive on price in Abad (1994) model and both of seller and buyer choose cooperative condition. Abad and Jaggi (2003) consider a model which seller offers trade credit to the buyer. Sucky (2005) Sucky (2006), Heuvel et al (2007) and Dai and Qi (2007) determine the optimal order quantity or order cycles for optimizing their objective functions of seller and buyer. In those models demand rate is fixed and seller and buyer both select cooperative condition.

Also, Abad (1994), Kim \& Lee (1993), Kim \& Lee (1998a), Lee \& Kim (1998b) and Jung \& Klein (2001), Jung \& Klein (2005) calculate the optimal price and order quantity by joint lot sizing and pricing approaches. They assumed that price is related to demand. On the other hand, Freeland (1980), Kim \& Lee (1993), and Sajadi et al (2005) assumed that demand is influenced by marketing expenditure and pricing together. But, Esmaeili et al (2009) found that no interaction between supply chain members is considered in these models.

Kotler (1997) extended the previous researches by considering the role of marketing, advertising, sales promotion and sales force. Roghanian et al (2007) proposed model of supply chain in a "probabilistic bi-level linear multi-objective programming problem". The model was assumed in a deterministic, fuzzy programming and etc conditions.

Zitoa et al (2011) presented a competitive environment in bi-level optimization program for explaining operative decisions on fares and frequencies of service. They were modeling airlines' choices in duopoly market with game theory. Their work was focused on how in a competitive situation the airlines decide.

Chiou et al (2013) presented two bi-level programming models and operational model for the intercity passenger transport systems under sustainability. The upper-level models (the government) provided the transport infrastructures and decided about the fares (tolls) to achieve some sustainability objectives, indexed by energy consumption, air pollution, traffic safety, and travel time. The lower-level models (the transport carriers) hopped to determine the service frequencies to maximize their profits and the users aimed to maximize their utilities. The models were solved by game theory.

Hjaila et al (2015) presented a scenario-based negotiation (SBN) win-to-win approach for optimizing coordinated decentralized multi-site multi-product Supply Chains (SCs) in a competitive environment. They assumed a non-symmetric roles where the leader aimed to settle its offer taking into account the reaction of the follower which is uncertain. Different negotiation scenarios were analyzed.

In this paper we present a method for developing the model which was presented in Esmaeili et al (2009). In that paper, it is supposed that the seller and buyer decision under seller and buyer-Stackelberg models.

The production rate of the seller in Esmaeili et al (2009) is assumed linear. The production rate of seller is also based on the rate of market demand. In their model demand is sensitive to selling price and marketing expenditure. Their relationship is as follow:

$\mathrm{D}=\mathrm{K} \cdot \mathrm{P}^{\mathrm{a}} \cdot \mathrm{M}^{\mathrm{b}}$

In this paper, the problem is formulated as a bi-level form in which the upper level sub problem is for seller and maximizes the seller's profit. Although there are some similarity between our model and Esmaeili et al (2009), but at their models the effects of other opponents are not considered. It means that, Esmaeili et al (2009) consider one seller and buyer but we extended the model for $n$ seller and one buyer. Also, sellers are face with the lower level sub-problem that solves the buyers function.

An important feature of this type of problem, and more generally of bi-level programs, is the existence of hierarchical relationship between decision makers.

In this paper, a game theory approach has been developed in order to simulate the supply chains' behaviour with competitive suppliers and one retailer.

This paper is organized as follows. The basic concepts of game theory especially Nash equilibrium and also bi-level programming are explained in Section 2. Section 3 describes the main problem formulation. Section 4 debates the proposed solution methods. Section 5 provides an illustrative example. Section 6 gives the conclusion. 


\section{Basic Concepts}

In this section we review the Nash equilibrium as one of the basic concepts of game theory, Supply Function Equilibrium (SFE) and then bi-level programming is noticed.

\subsection{Game Theory}

In this paper, the optimum price selecting strategies of each seller are solved by obtaining Nash equilibrium which is one the most important concept of game theory.

Here, we review the definition of Nash equilibrium. Generally, game theory is speaking about the problems between multi-person and multi-firm. Game theory is usually study about three important models of mathematics which is strategic form, extensive and coalitional form, Blake (2003). The approaches which are mentioned are different on using the detail for modeling the game. We choose the strategic form, so we explain the basic concept of mentioned form.

Suppose that $(S, f)$ be a game with $n$ players. $S_{i}$ is the strategy set for player $j, S=S_{1} X S_{2} \ldots X S_{n}$ is the set of strategy profiles and also $\mathrm{u}=\left(\mathrm{u}_{1}(\mathrm{x}), \ldots, \mathrm{u}_{\mathrm{n}}(\mathrm{x})\right)$ is the payoff function of playing the game. $\mathrm{x}_{-\mathrm{j}}$ is a strategy profile of all players $\{1, \ldots, n\}$ except for player $\mathrm{j}$. When player $\mathrm{j} \in\{1, \ldots, \mathrm{n}\}$ chooses strategy $\mathrm{x}_{\mathrm{j}}$ it results to strategy profile of $x=\left(x_{j}, \ldots, x_{n}\right)$. Therefore, player $j$ obtain payoff $u_{j}(x)$. The payoff depends on the strategy profile chosen (on the strategy chosen by player $\mathrm{j}$ and also the strategies chosen by all the other players). A strategy profile $x^{*} \in S$ is a Nash equilibrium (NE) if and only if for any single player $j$, no unilateral deviation in strategy is profitable.

$\forall j, x_{j} \in S_{j}, x_{j} \neq x_{j}^{*}: f_{j}\left(x_{j}^{*}, x_{-j}^{*}\right) \geq f_{j}\left(x_{j}, x_{-j}^{*}\right)$, Soleymani et al (2007).

So, Nash equilibrium point is a best response for the problem in the situation which no player has any incentive to deviate from that point.

In the SFE (supply function equilibrium) models, each player competes simultaneously with the other opponents. So in this research we use this model for our problem. Fig. 1 illustrates the competitive spectrum of four known model in imperfect information. These models are as follow:

1. Bertrand

2. Cournot

3. Stackelberg

4. SFE

For more explanation about these four models refer to Blake (2003). In these four models, it is just SFE model which procure a situation for choosing the both price and demand quantity for the players. The price choosing strategy for each seller is as bellow:

$\mathrm{Mc}_{j}$ is the marginal cost for each seller.

$$
\begin{gathered}
V_{j}=M c_{j}+\mu_{j} \times D_{j}=\left(C_{s_{j}}+\frac{A_{s_{j}}}{Q_{j}}\right) \cdot D_{j}+\mu_{j} \cdot D_{j}=\left(C_{s_{j}}+\frac{A_{s_{j}}}{Q_{j}}+\mu_{j}\right) \cdot D_{j} \\
=\delta_{j} \cdot D_{j}+\gamma_{j} \\
, \gamma_{j}=0
\end{gathered}
$$

Where $\delta$ is parameterization and $\gamma$ is a fixed pre chosen amount in our model.

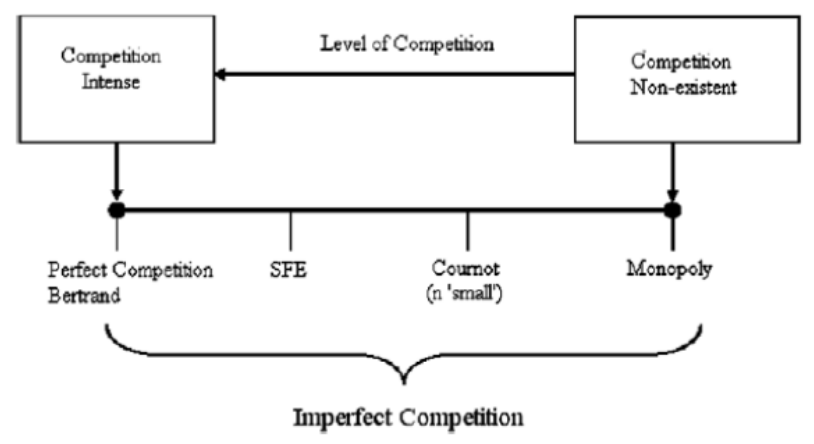

Figure 1. Equilibrium models and predicted degree of competition, Blake (2003) 


\subsection{Bi-Level Programming}

Bi-level programming problem is creating a suitable and successively decision making condition for two decision-makers, Emam (2005).

In the bi-level programming (BLP) problem, two decision makers exist. Each of the agents has a great interest in optimizing own object(s) as much as available. Their preferences are limited because of other agent goals(s). Generally, their selected strategy has an important affects on the other, Roghanian et al (2007).

General formulation of a bi-level programming problem (BLPP) is presented here, (Colson and et al, 2005):

$$
\begin{gathered}
\min _{x} F(x, y) \\
\text { s.t. } G(x, y) \leq 0, \\
\min _{y} f(x, y) \\
\text { st. } g(x, y) \leq 0,
\end{gathered}
$$

In bi-level programming there are two categories of variables: $x$ and $y \rightarrow x \in R^{n 1}$ and $y \in R^{n 2}$. First class of variables is the upper-level and is named " $x$ ". The second class is the lower-level and is called"y". Also, there are two categories for objective functions. F: $\mathrm{R}^{\mathrm{n} 1} \times \mathrm{R}^{\mathrm{n} 2} \rightarrow \mathrm{R}$ Is the upper-level object function and $\mathrm{f}: \mathrm{R}^{\mathrm{n} 1} \times \mathrm{R}^{\mathrm{n} 2} \rightarrow$ $R$ is the lower-level object function. Vector valued functions $G: R^{n 1} \times R^{n 2} \rightarrow R^{m 1}$ and $g: R^{n 1} \times R^{n 2} \rightarrow$ $\mathrm{R}^{\mathrm{m} 1}$ are called upper-level and lower-level constraints. All of the parameters and variables in constraints and objective functions can be linear, non-linear, fractional and etc, Roghanian et al. (2007).

\section{Problem Formulation}

In this section at first the notation and formulations which are used in our model are introduced. Then the formulation of the main problem is explained.

\subsection{Assumption}

Some Assumptions are imposed in the proposed models, these notation are assumed in other models, see Esmaeili et al (2009):

1. Infinite horizon of planning is exists.

2. In these models Lot size is determined by the buyer in seller-buyer supply chain.

3. Shortages must not be happened.

4. All Parameters of proposed models are deterministic.

5. $A_{S}>A_{b}$ is assumed. Also, $D=K P^{-\alpha} M^{\beta}$, see Lee and Kim (1993).

In these models demand function is not assumed to be constant such as some other researchers done, see (Abad, 1994; Kim \& Lee, 1993; Lee et al, 1996; Kim and Lee, 1998; Jung \& Klein, 2001; Jung \& Klein 2005; Esmaeili et al, 2009).

\subsection{Notation and Problem Formulation}

In this section object functions and input parameters of our proposed models are explained. Some of these notation are used in, Esmaeili et al, (2009).

\subsection{Object Functions}

$\pi_{\mathrm{s}}(\mathrm{j})$ : the seller profit.

$\pi_{\mathrm{b}}$ : the buyer profit.

Decision variables:

$\mathrm{V}$ : the price charged by the sellers to the buyer and is accepted. (\$/unit)

Voffered(j): the price offered by seller to the buyer.

$\mathrm{Q}(\mathrm{j})$ : lot size (units) determined by the seller.

P: selling price charged by the buyer. (\$/unit)

M: marketing expenditure incurred by the buyer. (\$/unit).

$\mathrm{A}_{\mathrm{s}}$ : seller's setup. (Ordering cost) (\$/setup)

$\mathrm{C}_{\mathrm{S}}$ : seller's production cost including purchasing cost. (\$/unit)

Dofferedmax (j):maximum demand satisfaction level of seller $\mathrm{j}$.

Dofferedmin(j):minimum stable demand of seller $\mathrm{j}$.

Doffered(j): demand for satisfying to be offered by seller $\mathrm{j}$ above the minimum offered demand.

$D(j): D_{\text {offered }}(j)+D_{\text {offeredmin }}(j)$

ST(j):state of seller $\mathrm{j}$. if 1 , the seller will be satisfied to offered demand in defined constraint. Otherwise it would be equal zero.

Dwon(i): the accepted demand for seller $\mathrm{j}$ from the retailer. 
Dnew (j):Dwon(j)+ Dofferedmin(j)

STnew(j):the state of seller $j$, in the buyer point of view.

$\mu(j)$ :mark-up coefficient of seller $j$.

\section{Input Parameters}

$\mathrm{k}$ : scaling constant for demand function. $(\mathrm{k}>0)$

i: percent inventory holding cost per unit per year.

$\alpha$ : price elasticity of demand function. $(\alpha \geq 1)$

$\beta$ : marketing expenditure elasticity of demand. $(2<\alpha-\beta, 0<\beta<1, \mu(\alpha-\beta)<1)$

$A_{b}$ : buyer's ordering cost. (\$/order)

$\mathrm{D}(\mathrm{P}, \mathrm{M})$ : total annual demand; for notational simplicity we let. $\mathrm{D}=\mathrm{D}(\mathrm{P}, \mathrm{M})$

$\mathrm{j}$ :the suffix of seller.

For each seller, hers object is calculated as jth Seller's profit $=$ jth Sales revenue - jth Production cost - jth Setup cost.

And also the object of buyer is calculated as Buyer's profit $=$ Sales revenue - Purchase cost - Market cost Ordering cost -Holding cost.

Note that, in the proposed model exist $\mathrm{n}$ seller, which have competition for achieving the market demand under the capacities constraints, demand constraints and.... Theses constraints would be explained briefly later.

Therefore, our function is formulated as follow:

\subsection{Estimating Opponents Unknown Information for Each Seller}

Actually, each of the sellers does not have any information about other sellers. Also, if they have some information, it will be imperfect. In spite of these imperfections, sellers need to guess their opponents' behavior for future periods.

It is supposed that the costs of each seller are contains seller's production cost plus seller's setup, Esmaeili et al (2009):

$$
C_{S} D(j)+A_{S} \frac{D(j)}{Q(j)}
$$

It is supposed that, each seller has only the knowledge about the minimum and maximum demand levels that its opponents could satisfied as well as costs information.

In this section, profit maximization is applied for finding the optimal decisions-making variables quantity of each seller individually. This problem is considered as the upper problem in our bi-level programming problem without regarding to the objects and constraints of other seller. On the other hand, sellers are supposed as leader, but noticed that, in reality the buyer is selecting its sellers and amount of productions would be purchased from each seller.

Here the objective function jth seller with regards to its constraints is modeled.

$$
\begin{aligned}
& \operatorname{Max\pi s}(j)=\operatorname{voffered}(j) D(j)-C_{S}(j) D(j)-A_{S}(j) \frac{D(j)}{Q(j)} \\
& \text { st: } \\
& \operatorname{voffered}(j)=R(j) \cdot\left(C_{S}(j)+A_{S}(j) \cdot Q(j)^{-1}\right) \\
& \sum_{i=1}^{n} D(j) \geq D \\
& D(j) \leq\left(D_{\max }(j)-D_{\min }(j)\right) \cdot S T(j) \\
& D(j)=\left(D_{\text {offered }}(j)+D_{\min }(j) \cdot S T(j)\right)
\end{aligned}
$$

In this model voffered $(j)$ is as voffered $(j)=R(j) \cdot\left(C_{S}(j)+A_{S}(j) \cdot Q(j)^{-1}\right)$

Consequently:

$$
\operatorname{voffered}(j) \geq C_{S}(j)+A_{S}(j) \cdot Q(j)^{-1}
$$


Therefore the constraint of (4) is substitute with (5), as follow:

$$
\begin{aligned}
& \operatorname{Max} \pi s(j)=\text { voffered }(j) D(j)-C_{S}(j) D(j)-A_{S}(j) \cdot \frac{D(j)}{Q(j)} \\
& \text { st: } \\
& \operatorname{voffered}(j) \geq C_{S}(j)+A_{S}(j) \cdot Q(j)^{-1} \\
& \sum_{i=1}^{n} D(j) \geq D \\
& D(j) \leq\left(D_{\max }(j)-D_{\text {min }}(j)\right) \cdot S T(j) \\
& D(j)=\left(D_{\text {offered }}(j)+D_{\min }(j) \cdot S T(j)\right)
\end{aligned}
$$

Actually, the proposed model in (7) is calculated for offered amounts of demand and price to the buyer. So the real obtained profit of each seller is different from what is mentioned. The proper amount of profit for each seller would be shown later in section 4 . These amounts are calculated by awarded amount of demand by buyer to each seller and accepted price.

\section{The Proposed Solution Method}

In this section, the profit function for the buyer should be defined. The profit function of buyer is calculated after seller selecting. The profit function for the buyer with regarding to its constraint is called the lower sub-problem. This model is solved by using the results of section 3.3.

$$
\begin{aligned}
& \text { Max } \pi b=P \cdot \sum_{j=1}^{n} D_{\text {new }}(j)-M \cdot \sum_{j=1}^{n} D_{\text {new }}(j)-\sum_{j=1}^{n} A_{b} \cdot \frac{D_{\text {new }}(j)}{Q(j)}-0 \cdot 5 i \cdot \sum_{j=1}^{n} Q(j) \cdot v(j)-\sum_{i=1}^{n} D_{\text {new }}(j) \cdot v(j) \\
& \text { st: } \\
& P(j)=\frac{\alpha\left(v(j)+A_{b} Q(j)^{-1}\right)}{\alpha-\beta-1} \\
& M(j)=\frac{\beta\left(v(j)+A_{b} Q(j)^{-1}\right)}{\alpha-\beta-1} \\
& P=\frac{\sum_{j=1}^{n} P(j) \cdot D_{\text {new }}(j)}{\sum_{j=1}^{n} D_{\text {new }}(j)} \\
& M=\frac{\sum_{j=1}^{n} M(j) \cdot D_{\text {new }}(j)}{\sum_{j=1}^{n} D_{\text {new }}(j)} \\
& Q(j)=\sqrt{\frac{\left.2 A_{b} D_{\text {new }}(j)\right)}{i \cdot v(j)}} \\
& Q(j) \geq \frac{A_{b}}{v(j)}\left(\frac{\alpha-\beta-2}{2}\right) \\
& D_{\text {won }}(j) \leq D_{\text {offered }}(j) \cdot S T(j) \\
& D_{\text {won }}(j) \leq D_{\text {offered }}(j) \cdot S T_{\text {new }}(j) \\
& S T_{\text {new }}(j) \leq S T(j) \\
& D_{\text {new }}(j)=\left(D_{\text {offered }}(j)+D_{\text {min }}(j) \cdot S T_{\text {new }}(j)\right)
\end{aligned}
$$


Note that each seller could offer and also awarded individual demand and then calculate optimize price for its productions. But, when the buyer selects its seller and the amounts of productions and the agreed price for purchasing the production from each seller in the market, the obtained profit of each seller is changed from what was explained in section 3.3. The benefit function for jth seller with regard to its explained constraint and also substituting (9) :

$$
D_{\text {new }}(i)=\left(D_{\text {offered }}(i)+D_{\text {min }}(i) \cdot S T_{\text {new }}(i)\right)
$$

Is as follow:

$$
\begin{aligned}
& \operatorname{Max} \pi s(j)=v\left(D_{\text {offered }}(j)+D_{\min }(j) \cdot S T_{\text {new }}(i)\right)-C_{S}\left(D_{\text {offered }}(j)+D_{\min }(j) \cdot S T_{\text {new }}(i)\right) \\
& -A_{S} \frac{D_{\text {new }}(i)}{Q(j)}
\end{aligned}
$$

\section{Solution Methods}

In this section the offered amounts of all sellers are analyzed for obtaining the Nash equilibrium and selecting the best strategy for each seller and also the buyer.

Here with considering Soleymani et al (2007), Soleymani et al (2008) which is presented bidding strategies for generating companies in energy market we proposed the solution method.

This decision making is a kind of game. The obtained Nash equilibrium point might be individual, several or it may be empty.

As mentioned before, each seller tries to choose the best and optimize strategy for themselves. Each seller has complete information about their own costs, but not about the other costs. So they should model other sellers' behavior with imperfect information. Hence, all the sellers are intelligent; they choose Nash equilibrium as their best strategy selecting.

The method, is explained follow, is for calculating the updating strategy selecting for sellers and buyer:

a. Setting the initial value for $C_{s}, A_{s}$ and $\theta$ for each seller.

b. Supposing that $C_{s}, A_{s}$ and $\mu$ for all sellers except seller $\mathrm{j}$ is fixed and then the strategy of seller $\mathrm{j}$ should be update until it reaches a stage that she has no intend to change that.

c. Repeat stage (b) for all sellers.

d. Go to stage (b) and repeat these procedures until none of the sellers changes her strategy.

Fig.2 illustrates the whole levels of optimal strategies of decision making for sellers and buyer. If no Nash equilibrium is found it means that because of some constraint in model there are no strategies with results to a point that all sellers and buyer be agreed on that.

\section{Computational Results}

\subsection{Numerical Example}

In this section a numerical example is used for illustrating better the applied model. In this example there is exist ten sellers and one buyer and it is consider as the total market. It means that the total demand is considered as the demand of this single buyer. Fig.3 shows the proposed example.

The parameters which are used in this model are as follow:

$\mathrm{K}=3500, \beta=0.15, \alpha=1.7, \mathrm{i}=10 \%, \mathrm{~A}_{\mathrm{b}}=40, \mathrm{u}=1, \mathrm{n}=10$ 


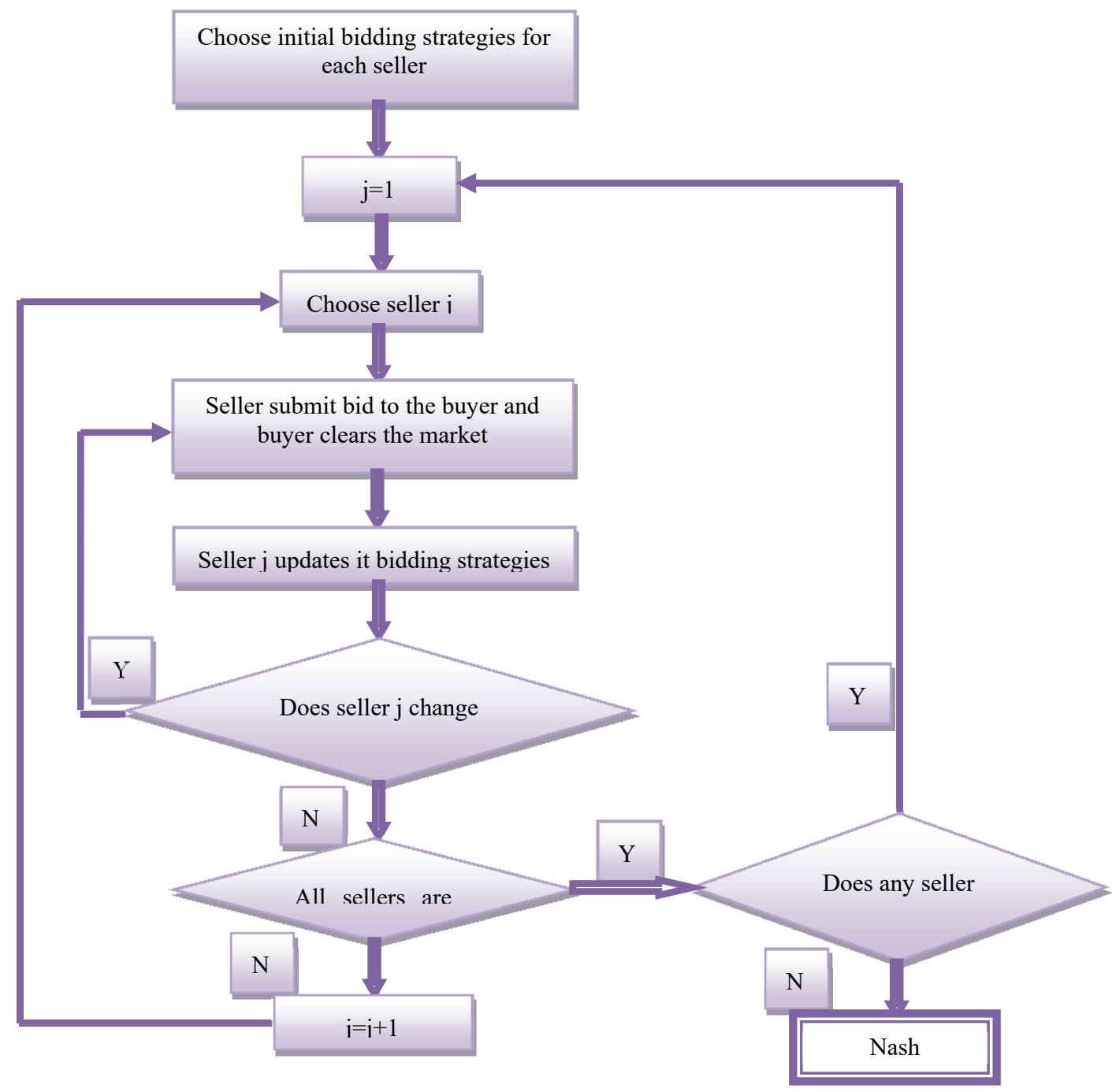

Figure 2. procedure of optimal decision making
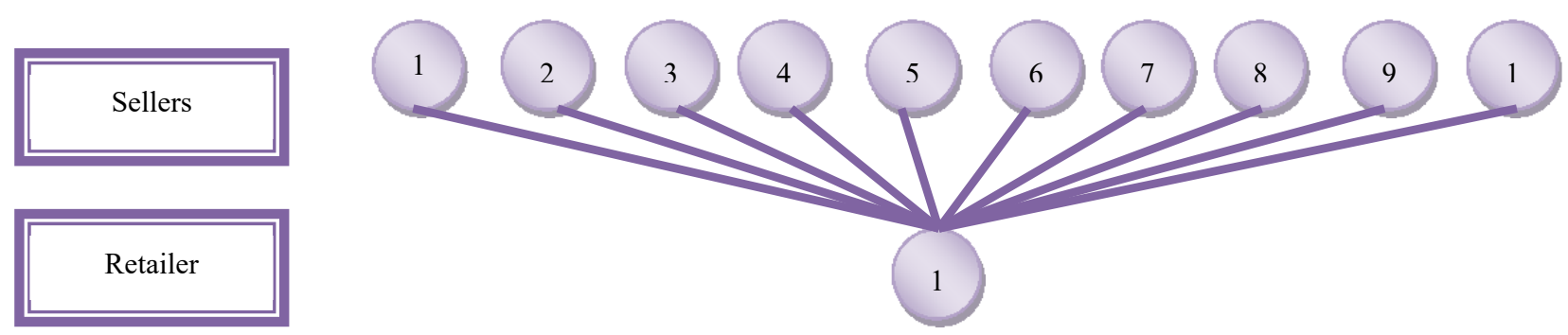

Figure 3.10 sellers and 1 buyer model

Table1. seller-buyer supply chain data

\begin{tabular}{ccccc}
\hline & $\operatorname{Dmin}(\mathrm{j})$ & $\operatorname{Dmax}(\mathrm{j})$ & $\mathrm{A}_{\mathrm{S}}(\mathrm{j})$ & $\mathrm{C}_{\mathrm{S}}(\mathrm{j})$ \\
\hline 1 & 25 & 100 & 40 & 1.5 \\
2 & 25 & 100 & 40 & 1.5 \\
3 & 25 & 100 & 40 & 1.5 \\
4 & 25 & 100 & 40 & 1.5 \\
5 & 25 & 100 & 40 & 1.5 \\
\hline
\end{tabular}




\begin{tabular}{ccccc}
\hline 6 & 25 & 100 & 40 & 1.5 \\
7 & 25 & 100 & 40 & 1.5 \\
8 & 25 & 100 & 40 & 1.5 \\
9 & 25 & 100 & 40 & 1.5 \\
10 & 25 & 100 & 40 & 1.5 \\
\hline
\end{tabular}

Table 2. the results of Nash equilibrium for sellers

\begin{tabular}{ccc}
\hline & $\mathrm{D}(\mathrm{j})$ & $\left.\pi_{\mathrm{s}} \mathrm{j}\right)$ \\
\hline 1 & 93.603 & 398.897 \\
2 & 96.525 & 411.350 \\
3 & 65.403 & 278.721 \\
4 & 60.825 & 259.213 \\
5 & 94.986 & 404.794 \\
6 & 56.557 & 241.025 \\
7 & 38.141 & 162.542 \\
8 & 25.000 & 106.54 \\
9 & 90.480 & 385.589 \\
10 & 48.969 & 208.687 \\
\hline
\end{tabular}

Table 3. the results of Nash equilibrium for buyer

\begin{tabular}{cccc}
\hline $\mathrm{M}$ & $\mathrm{P}$ & $\pi_{\mathrm{b}}$ & $\mathrm{V}$ \\
\hline 0.895 & 10.142 & 1790.667 & 5.512 \\
\hline
\end{tabular}

\subsection{Sensitivity Analysis}

In this section the effects of parameters $\alpha$ and $\beta$ are showed. With considering the limitation of $\alpha$ and $\beta$ we solve the model for different amounts of these two parameters. The results of this reputation are in table 4 and 5 , also Figure 4 and Figure 5.

As is seen in Fig .4, decision variables decreasing by increasing $\alpha$. Also as Figure 5 shows, $\mathrm{M}$ and $\mathrm{P}$ are increasing and $\mathrm{V}$ is approximately unchanged by increasing $\beta$. This results are same as Esmaeili et a (2009).

Table 4. The effect of parameters $\alpha$ on $\mathrm{M}^{*}, \mathrm{~V}^{*}$ and $\mathrm{P}^{*}$

\begin{tabular}{llll}
\hline$\alpha$ & $\mathrm{M}$ & $\mathrm{V}$ & $\mathrm{P}$ \\
\hline 1.7 & 0.895 & 5.512 & 10.142 \\
2.2 & 0.554 & 3.454 & 8.122 \\
2.4 & 0.494 & 3.094 & 7.906 \\
\hline
\end{tabular}

Table 5. The effect of parameters $\alpha$ on $\mathrm{M}^{*}, \mathrm{~V}^{*}$ and $\mathrm{P}^{*}$

\begin{tabular}{llll}
\hline$\beta$ & $\mathrm{M}$ & $\mathrm{V}$ & $\mathrm{P}$ \\
\hline 0.08 & 0.498 & 5.82 & 10.58 \\
0.15 & 0.895 & 5.512 & 10.142 \\
0.17 & 1.005 & 5.441 & 10.052 \\
0.2 & 1.173 & 5.365 & 9.97 \\
0.3 & 3.418 & 5.586 & 11.622 \\
0.6 & 5.066 & 5.944 & 14.355 \\
\hline
\end{tabular}




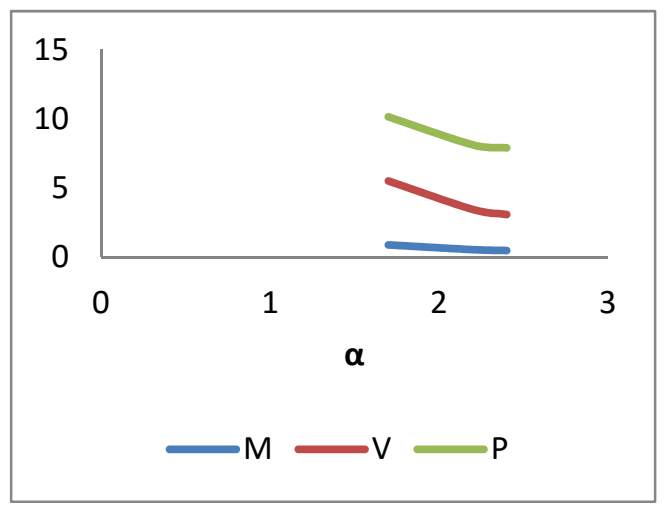

Figure 4. The effect of parameters $\alpha$ on $\mathrm{M}^{*}, \mathrm{~V}^{*}$ and $\mathrm{P}^{*}$

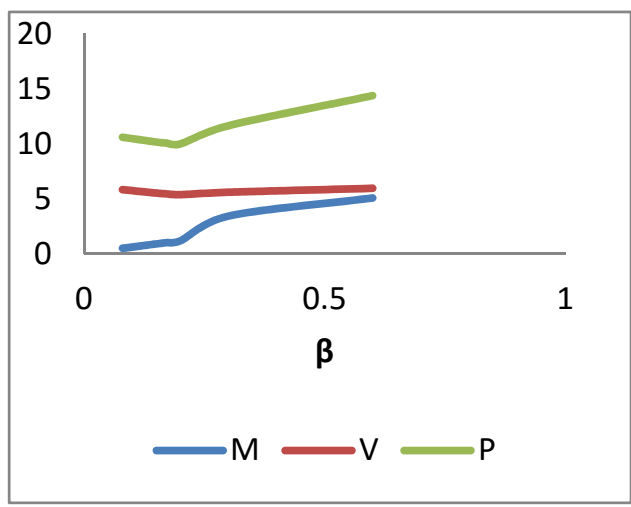

Figure 5. The effect of parameters $\beta$ on $\mathrm{M}^{*}, \mathrm{~V}^{*}$ and $\mathrm{P}^{*}$

\section{Conclusion}

The problem of seller-buyer in a supply chain management is considered in Bi-level form (BLP problem) in this paper. In our proposed model, the production rate is linear and also is change with the market demand rate. Demand is function of selling price and marketing expenditure.

In this paper it is assumed that there is finite number of seller and one buyer that is considered as the whole market of consumption.

Each seller or player in this market should be able to choose a proper pricing strategy for maximizing its own profit. But there are some constraints that limit seller's actions.

A new approach is proposed here for selecting the pricing strategy of sellers. The proposed method is based on the action of each seller, reaction of its opponents and reaction of buyer. A numerical example is applied for illustrating the proposed method.

\section{References}

Abad, P. L. (1994). Supplier pricing and lot sizing when demand is price sensitive. European Journal of Operational Research, 78(3), 334-354. http://dx.doi.org /10.1016/0377-2217(94)90044-2

Abad, P. L., \& Jaggi, C. K. (2003). A joint approach for setting unit price and the length of the credit period for a seller when end demand is price sensitive. International Journal of Production Economics, 83(2), 115122. http://dx.doi.org /10.1016/s0925-5273(02)00142-1

Blake, M. (2003). Game theory and electricity markets. Drayton Analytics Research Paper Series. Retrieved from http://www.ibrarian.net/navon/paper/Game_Theory_and_Electricity_Markets.pdf?paperid=10948295

Chen, M. S., Chang, H. J., Huang, C. W., \& Liao, C. N. (2006). Channel coordination and transaction cost: A game-theoretic analysis. Industrial Marketing Management, $\quad 35(2), \quad 178-190$. http://dx.doi.org/10.1016/j.indmarman.2005.03.007

Chiang, W. C., Fitzsimmons, J., Huang, Z., \& Li, S. X. (1994). A Game-Theoretic Approach to Quantity 
Discount Problems. Decision $\quad$ Sciences, $153-168$. http://dx.doi.org/10.1111/j.1540-5915.1994.tb00521.x

Chiou, Y. C., Lan, L. W., \& Chang, K. L. (2013). Sustainable consumption, production and infrastructure construction for operating and planning intercity passenger transport systems. Journal of Cleaner Production, 40, 13-21. http://dx.doi.org /10.1016/j.jclepro.2010.09.004

Colson, B., Marcotte, P., \& Savard, G. (2005). Bilevel programming: A survey. 4OR, 3(2), 87-107. http://dx.doi.org/10.1007/s10288-005-0071-0

Corbett, C. J., \& de Groote, X., (2000). A supplier's optimal quantity discount policy under asymmetric information. Management Science, 46(3), 444-450. http://dx.doi.org/10.1287/mnsc.46.3.444.12065

Dai, T., \& Qi, X. (2007). An acquisition policy for a multi-supplier system with a finite-time horizon. Computers \& Operations Research, 34(9), 2758-2773. http://dx.doi.org/10.1016/j.cor.2005.10.011

Dai, Y., Chao, X., Fang, S. C., \& Nuttle, H. L. W. (2005). Pricing in revenue management for multiple firms competing for customers. International Journal of Production Economics, 98(1), 1-16. http://dx.doi.org/10.1016/j.ijpe.2004.06.056

Emam, O. E. (2006). A fuzzy approach for bi-level integer non-linear programming problem. Applied Mathematics and Computation, 172(1), 62-71. http://dx.doi.org /10.1016/j.amc.2005.01.149

Esmaeili, M., Aryanezhad, M. B., \& Zeephongsekul, P. (2009). A game theory approach in seller-buyer supply chain. European Journal of Operational Research, 195(2), $442-448$. http://dx.doi.org/10.1016/j.ejor.2008.02.026

Ferrero, R. W., Rivera, J. F., \& Shahidehpour, S. M. (1998). Application of games with incomplete information for pricing electricity in deregulated power pools. IEEE Transactions on Power Systems, 13(1), $184-189$. http://dx.doi.org/10.1109/59.651634

Freeland, J. R. (1980). Coordination Strategies for Production and Marketing in a Functionally Decentralized Firm. A I I E Transactions, 12(2), 126-132. http://dx.doi.org /10.1080/05695558008974499

Heuvel, W. van den, Borm, P., \& Hamers, H. (2007). Economic lot-sizing games. European Journal of Operational Research, 176(2), 1117-1130. http://dx.doi.org /10.1016/j.ejor.2005.09.011

Hjaila, K., Puigjaner, L., \& Espuña, A. (2015). Scenario-Based Price Negotiations vs. Game Theory in the Optimization of Coordinated Supply Chains. Computer Aided Chemical Engineering, 1859-1864. http://dx.doi.org /10.1016/b978-0-444-63576-1.50004-2

Jung, H., \& Klein, C. M. (2001). Optimal inventory policies under decreasing cost functions via geometric programming. European Journal of Operational Research, 132(3), 628-642. http://dx.doi.org/10.1016/s0377-2217(00)00168-5

Jung, H., \& Klein, C. M. (2005). Optimal inventory policies for an economic order quantity model with decreasing cost functions. European Journal of Operational Research, 165(1), $108-126$. http://dx.doi.org/10.1016/j.ejor.2002.01.001

Kim, D., \& Lee, W. J. (1998a). Optimal joint pricing and lot sizing with fixed and variable capacity. European Journal of Operational Research, 109(1), 212-227. http://dx.doi.org/10.1016/s0377-2217(97)00100-8

Kim, D., \& Lee, W. J. (1998b). Optimal coordination strategies for production and marketing decisions. Operations Research Letters, 22(1), 41-47. doi: http://dx.doi.org /10.1016/s0167-6377(97)00052-7

Kotler, P. (1997). Marketing Management, Analysis, Planning Implementation, and Control. Prentics Hall International Inc. Retrieved from http://www.amazon.com/Marketing-Management-Analysis-Implementation-Prentice-Hall/dp/0137228511

Lee, W. J. (1993). Determining Order Quantity and Selling Price by Geometric Programming: Optimal Solution, Bounds, and Sensitivity. Decision $\quad$ Sciences, $\quad 24(1), \quad 76-87$. http://dx.doi.org/10.1111/j.1540-5915.1993.tb00463.x

Lee, W. J., \& Kim, D. (1993). Optimal and Heuristic Decision Strategies for Integrated Production and Marketing Planning. Decision $1203-1214$. http://dx.doi.org/10.1111/j.1540-5915.1993.tb00511.x

Roghanian, E., Sadjadi, S. J., \& Aryanezhad, M. B. (2007). A probabilistic bi-level linear multi-objective programming problem to supply chain planning. Applied Mathematics and Computation, 188(1), 786- 
800. http://dx.doi.org/10.1016/j.amc.2006.10.032

Sadjadi, S. J., Oroujee, M., \& Aryanezhad, M. B. (2005). Optimal Production and Marketing Planning. Computational Optimization and Aplications, 30(2), 195-203. http://dx.doi.org/10.1007/s10589-005-4564-8

Shahidehpour, M., Yamin, H., \& Li, Z. (2002). Market operation in electric power systems. New York: Wiley. Retrieved from http://ieeexplore.ieee.org/book/0471463949.pdf

Soleymani, S., Ranjbar, A. M., \& Shirani, A. R. (2007). New approach for strategic bidding of Gencos in energy and spinning reserve markets. Energy Conversion and Management, 48(7), 2044-2052. http://dx.doi.org/10.1016/j.enconman.2007.01.002

Soleymani, S., Ranjbar, A. M., \& Shirani, A. R. (2008). New approach to bidding strategies of generating companies in day ahead energy market. Energy Conversion and Management, 49(6), 1493-1499. http://dx.doi.org/10.1016/j.enconman.2007.12.033

Sucky, E. (2005). Inventory management in supply chains: A bargaining problem. International Journal of Production Economics, 93-94, 253-262. http://dx.doi.org/10.1016/j.ijpe.2004.06.025

Sucky, E. (2006). A bargaining model with asymmetric information for a single supplier-single buyer problem. European Journal of Operational Research, 171(2), 516-535. http://dx.doi.org/10.1016/j.ejor.2004.08.039

Viswanathan, S., \& Wang, Q. (2003). Discount pricing decisions in distribution channels with price-sensitive demand. European Journal of Operational Research, 149(3), 571-587. http://dx.doi.org/10.1016/s0377-2217(02)00469-1

Yang, S. L., \& Zhou, Y. W. (2006). Two-echelon supply chain models: Considering duopolistic retailers' different competitive behaviors. International Journal of Production Economics, 103(1), 104-116. http://dx.doi.org/10.1016/j.ijpe.2005.06.001

Zito, P., Salvo, G., \& La Franca, L. (2011). Modelling Airlines Competition on Fares and Frequencies of Service by Bi-level Optimization. Procedia-Social and Behavioral Sciences, 20, 1080-1089. http://dx.doi.org/10.1016/j.sbspro.2011.08.117

\section{Copyrights}

Copyright for this article is retained by the author(s), with first publication rights granted to the journal.

This is an open-access article distributed under the terms and conditions of the Creative Commons Attribution license (http://creativecommons.org/licenses/by/3.0/). 